Vol. 17, No. 1, 2014, 1-6

http://dx.doi.org/10.5229/JKES.2014.17.1.1

\title{
$\mathrm{GaN}$ 를 이용한 광전기화학적 물분해
}

\author{
오일환* \\ 금오공과대학교 응용화학과
}

(2014년 1월 27일 접수 : 2014년 2월 15일 채택)

\section{Photoelectrochemical Water Splitting Using GaN}

\author{
Ilwhan $\mathrm{Oh}^{*}$ \\ Department of Applied Chemistry, Kumoh National Institute of Technology, Gumi, Korea
}

(Received January 27, 2013 : Accepted February 15, 2014)

\section{초 록}

본 총설은 질화 갈륨 $(\mathrm{GaN})$ 을 이용한 광전기화학적 물분해 연구에 대해 정리하였다. $\mathrm{GaN}$ 는 화 학적으로 안정하고 에너지 띠간격 조절이 자유롭다는 장점으로 최근 물분해를 위한 새로운 광전 극 물질로 연구되고 있다. 다른 화합물 반도체 물질은 강산 혹은 강염기 전해액에 의해 쉽게 부식되기 때문에 광산화전극(photoanode)으로는 사용이 어려운 반면, $\mathrm{n}$ 형 $\mathrm{GaN}$ 는 뛰어난 안정성 덕분에 산화 분위기의 산소 발생 전극으로도 활용이 가능하다. 또한, 최근에는 $\mathrm{p}$ 형 $\mathrm{GaN}$ 을 환원 전극으로 이용한 광전극에 대한 연구도 보고되었다. $\mathrm{GaN}$ 물질이 실제 응용되기 위해 필요한 과 제들에 대해 다루었다.

\begin{abstract}
This review article summarizes photoelectrochemical water splitting using gallium nitride $(\mathrm{GaN})$. GaN materials have been studied as novel photoelectrode material due to its chemical stability and easy band gap engineering. Unlike other semiconductor materials that are easily corroded in strongly acidic or alkaline electrolyte, n-type $\mathrm{GaN}$ is chemically stable enough to be used as photoanode in oxygen evolution reaction. Furthermore, studies on p-type $\mathrm{GaN}$ have been recently reported. This review briefly discusses problems that need to be solved before $\mathrm{GaN}$ materials find widespread use in solar fuel application.
\end{abstract}

Keywords : Gallium nitride, Water splitting, Chemical stability

\section{1. 서 론}

기존 화석연료에 기반한 에너지 시스템은 지구온난 화, 환경오염, 자원고갈 등의 문제를 일으키므로, 그 대안으로 이른바 '수소 경제(hydrogen economy)'가 제안되었다. 수소 경제란 기존 화석연료 대신에 수소 연료를 에너지 수송자 (energy carrier)로 사용하는 것 으로, 이를 실현하기 위한 가장 원천적이고 핵심적인 문제 중 하나는 수소 연료를 온실가스나 오염 물질을

*E-mail: ioh@kumoh.ac.kr
배출하지 않으면서 경제적으로 생산하는 것이다. ${ }^{1)}$ 최 근 전세계적인 관심과 연구 대상이 되고 있는 광전기 화학적 수소 생산법 (photoelectrochemical hydrogen production)은 반도체와 전해액 사이 계면에 태양광을 비춰 주어 계면에서 물분해를 수행하는데, 반도체/전 해액 계면이 광자를 흡수하여 그 에너지를 화학적 에 너지, 즉 수소 연료로 변환시키는 핵심적인 역할을 한 다. ${ }^{2}$ 광전극으로도 불리는 반도체 물질은 $\mathrm{Si}, \mathrm{GaAs}$ 등 단결정 물질부터 $\mathrm{TiO}_{2}$ 등 금속 산화물까지 다양한 물질들이 연구되고 있다. 1972년에 Fujishima와 Honda가 $\mathrm{TiO}_{2}$ 전극에 빛을 쪼여 줄 때 수소 발생이 
가능하다는 것을 보인 이후 ${ }^{3)}$ 수 많은 연구들이 진행 되었으나, 실용적인 소자를 구현하기 위해서는 크게 두 가지 문제점을 해결해야 한다.

첫째로, 광전극의 에너지 변환 효율을 높여야 한다. 태양광을 이용한 광전기화학적 수소 생산에서 에너지 변환 효율은 반도체 물질의 에너지 띠간격 (energy band gap)과 직결된다. 현재 대부분의 산화 금속 물질 $\left(\mathrm{TiO}_{2}, \mathrm{ZnO}\right.$ 등) 은 에너지 띠간격이 너무 커서 태양 광 스펙트럼 중 자외선 영역 광자만 흡수하고 다른 영역의 빛은 흡수하지 못하므로 이런 광전극들은 상당 히 작은 에너지 변환 효율을 나타낸다. 반면, $\mathrm{Si}, \mathrm{GaAs}$ 등 저에너지에서 중에너지 사이 띠간격 (low to $\mathrm{mid}$ band gap)을 갖는 반도체 물질들은 띠간격이 $1.0 \sim 1.5 \mathrm{eV}$ 사이이어서 적외선부터 자외선까지 대부분의 빛을 흡 수할 수 있다. 그러나, 외부로부터 전압 공급 없이 물 분해를 일으키기 위해서는 $1.5 \mathrm{~V}$ 이상의 광전압 (photovoltage)가 필요한데 일반적으로 이러한 광전극 들이 나타내는 광전압은 이에 비해 상당히 작다. 즉, 광전극의 에너지 띠간격 선택에 있어서 딜레마가 발 생한다.

두 번째로, 광전극의 신뢰성 (reliability) 도 중요한 이슈이다. 일반적인 발전소 규모 (utility scale) 태양전 지에 요구되는 수명이 15 20년임을 감안하면, 궁극적 으로 태양광 수소 생산기의 작동 수명도 이에 견줄 만 한 수준이 되어야 한다. 그러나 일반적으로 반도체 전 극은 부식되기 쉬운 물질이고, 강산이나 강염기성의 전 해액 속에서 지속적으로 태양광을 조사받기 때문에, 요 구되는 수명을 달성하기 매우 도전적인 상황이다.

이러한 광전기화학적 수소 생산에 대한 핵심 과제를 해결하기 위해 다양한 광전극 물질들이 개발되고 있다. 본 총설에서는 최근 새로운 광전극 물질로 관심을 받 고 있는 질화 갈륨 (Gallium nitride; $\mathrm{GaN}$ )에 대한 연 구 결과를 정리하였다. $\mathrm{GaN}$ 은 애초에 푸른 빛을 내는 발광다이오드 (light emitting diode; LED) 를 위해 개발되었다. 에너지 띠간격이 $3.4 \mathrm{eV}$ 로 $\mathrm{TiO}_{2}$ 수준이지 만, 성장과정에서 In 등을 첨가하여 합금을 만들어 줌 으로써 띠간격을 자유롭게 조절할 수 있다. Fig. 1에 나타내었듯이, 수소발생반응 (HER; hydrogen evolution reaction) 과 산소발생반응 (OER; oxygen evolution reaction) 전위가 $\mathrm{GaN}$ 의 전도띠 (conduction band) 및 결합띠 (valence band) 내에 포함되므로 (straddle), 에너지역학 면에서 외부 전위 없이 물분해를 수행할 수 있다. 또한 $\mathrm{Si}, \mathrm{GaAs}$ 등 다른 반도체 물질 에 비해 화학적 안정성이 매우 뛰어나서 강산, 강염기 환경의 전해질 환경에서 광환원전극(photocathode)으로 뿐 아니라 광산화전극(photoanode)으로도 사용될 수 있 다. 본 총설에서는 상대적으로 새로운 광전극 물질로

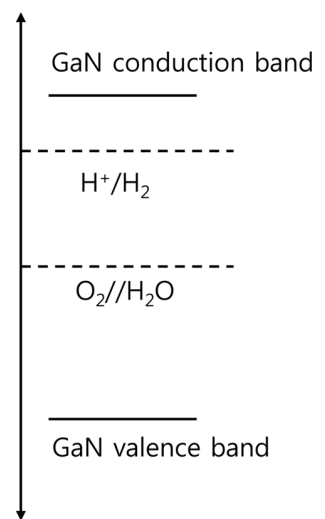

Fig. 1. The band-edge potentials of $\mathrm{GaN}$ in aqueous $1 \mathrm{M}$ KOH electrolyte $(\mathrm{pH}=14)$. The potentials of the hydrogen-evolving and the oxygen-evolving half-reaction are also plotted in the graph.

부상하고 있는 $\mathrm{GaN}$ 를 이용한 물분해 연구에 대해 검 토하고 향후 연구 과제들을 살펴 본다.

\section{2. $\mathrm{n}$ 형 $\mathrm{GaN}$ 물질의 산소발생반응을 이용한 광전기화학적 수소 생산}

$\mathrm{GaN}$ 성장시 불순물 (dopant)로 $\mathrm{Si}$ 을 첨가해 주면 3 족인 $\mathrm{Ga}$ 자리를 4족인 $\mathrm{Si}$ 이 치환하면서 자유전자가 전 도띠를 채우고 다수 캐리어 (majority carrier)가 되어서 $\mathrm{n}$ 형 반도체가 된다. $\mathrm{n}$ 형 $\mathrm{GaN}$ 을 전해액에 담그면 계면 근처의 다수 캐리어가 고갈 (depletion)되어 쇼트키 장 벽 (Schottky barrier)를 형성한다. 이 때 띠간격 이상 의 에너지를 갖는 광자가 들어오면 결합띠 (valence band)에 소수 캐리어 (minoriry carrier)인 정공 (hole) 이 생성되어 결핍층 (depletion layer)의 전기장에 의해 전해질 쪽으로 전달되고 산화반응을 일으킨다. 알칼리 물분해 셀 경우 다음의 산소 발생 반응을 일으킨다.

$$
2 \mathrm{OH}^{-}+2 h^{+} \rightarrow 1 / 2 \mathrm{O}_{2}(\mathrm{~g})+\mathrm{H}_{2} \mathrm{O}
$$

한편 상대전극에서는 다음의 수소 발생 반응이 일 어난다.

$$
2 \mathrm{H}_{2} \mathrm{O}+2 \mathrm{e}^{-} \rightarrow \mathrm{H}_{2}(\mathrm{~g})+2 \mathrm{OH}^{-}
$$

$\mathrm{GaN}$ 을 이용한 수소 생산에 대한 최초 논문은 Fujii 등이 2005년에 출간하였다.4) Fig. 2와 같이 광전기화학 셀을 구성하여 $\mathrm{n}-\mathrm{GaN}$ 광전극에서는 산소가, $\mathrm{Pt}$ 상대전 극에서는 수소가 발생토록 했다. Fig. 1의 에너지 띠 그림을 보면 외부 전압이 없어도 손쉽게 자발적으로 


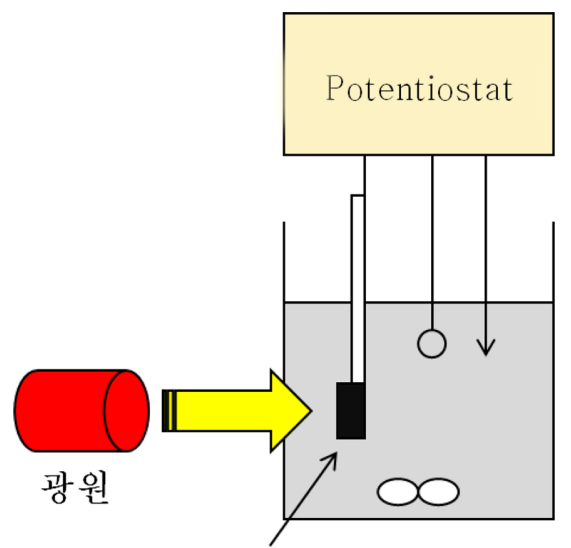

광전극

Fig. 2. Schematic diagram of photoelectrochemical cell with working electrode, reference electrode, and counter electrode.

물분해 반응이 진행되어야 한다. 그러나 예상과는 달리 short circuit $\left(V_{\mathrm{CE}}=0\right)$ 에서 광전류가 미미하고 상당한 외부 전압을 가해야 육안으로 수소 기포를 볼 수 있을 정도의 광전류가 흐른다. 이는 $\mathrm{GaN}$ 표면에 아무런 촉 매 물질이 없어서 산소 발생 반응에 상당한 과전압이 걸리기 때문이다.

한편 $\mathrm{GaN}$ 가 $\mathrm{KOH}$ 등 알칼리 용액에서 식각된다는 것은 잘 알려진 사실이다. 물분해 실험 전후 $\mathrm{GaN}$ 전 극의 무게를 측정하여 알칼리 용액에서 $\mathrm{n}$ 형 $\mathrm{GaN}$ 가 산화전극으로 사용될 때 다음의 부식 반응이 동시에 일어난다는 것이 밝혀 졌다.

$$
2 \mathrm{GaN}(\mathrm{s})+6 h^{+} \rightarrow 2 \mathrm{Ga}^{3+}+\mathrm{N}_{2}(\mathrm{~g})
$$

이 반응이 지속되면 $\mathrm{GaN}$ 광전극이 식각되어 그 활 성이 감소하게 된다. 중성 $(\mathrm{NaCl})$ 이나 산성 $(\mathrm{HCl})$ 전해액에서 물분해 반응을 진행시켜면 이러한 부식 반 응이 현저히 줄어듦이 보고되었다. ${ }^{5)}$

서론에서 언급한 바와 같이, $\mathrm{GaN}$ 의 에너지 띠간격 이 $3.4 \mathrm{e} \mathrm{V}$ 로 너무 커서 자외선 영역만을 흡수기 때문 에 에너지 변환 효율이 근본적으로 낮다. 태양광 스펙 트럼을 효율적으로 이용하지 못하는 문제를 해결하기 위해 $\mathrm{GaN}$ 결정격자에 $\mathrm{In}$ 이나 $\mathrm{Al}$ 등을 넣어 합금을 만 들어 띠간격을 줄여 광전류를 높이는 접근이 시도되 었다. ${ }^{6,7)}$ Fig. 3에 나타내었듯이, 첨가하는 $\mathrm{GaN}$ 결정 격자에 첨가되는 $\mathrm{In}$ 의 양이 증가하면 광전류도 증가되 었다. 이는 $\mathrm{In}$ 이 첨가될 수록 에너지 띠간격이 작아져 더 넓은 에너지 범위의 광자를 흡수해서 광전류가 증 가하기 때문이다.

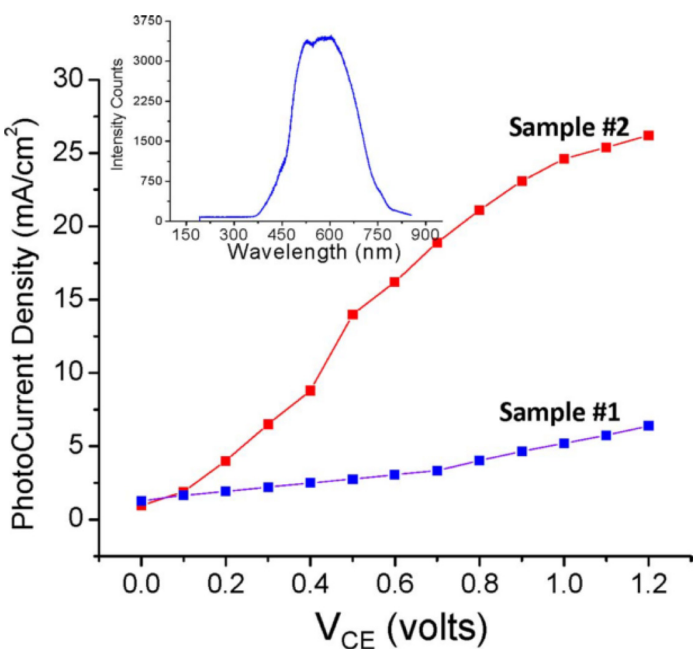

Fig. 3. Photocurrent density vs the bias voltage applied between the working and counter electrodes of InGaN based PEC. The results were obtained in aqueous $1 \mathrm{~mol} / \mathrm{L}$ $\mathrm{HCl}$ under static condition and white light illumination by using 2 different $n-\operatorname{In}_{x} G a_{1-x} N$ epilayers with $x=0.2$ and 0.4 as working electrodes. $\mathrm{H}_{2}$ generation is only visible when using sample 2 . The inset shows the emission spectrum of the white light source used for illumination. Reprinted with permission from ref. 7. Copyright 2010, AIP Publishing LLC.

$\mathrm{GaN}$ 는 그 특성상 부도체인 sapphire 기판 위에 성장시킨다. 따라서, 광전극 제조할 때 반도체와 금속 간 오믹 접촉 (ohmic contact)을 만들기 위해서 통상 적인 방법과 같이 후면(back side) 전기 접촉이 불가 하고 전면(front side) 전기 접촉을 해야 하는데, 이때 높은 저항에 의한 전류 과밀 (current crowding)이 발 생할 수 있다. 이러한 문제를 해결하기 위하여 $\mathrm{Liu}$ 등은 ${ }^{8)} \mathrm{ITO}$ 전극을 격자모양으로 $\mathrm{GaN}$ 표면에 패터닝 하여 광전극 전면적에 촘촘하게 오믹 접촉을 만들어서 광전류가 향상됨을 관찰하였다. 유사한 개념으로, Nakamura 그룹은 평평한 $\mathrm{GaN}$ 표면 위에 금속선 배열 을 형성한 후 선택 영역 성장 (selective area growth) 을 통해 $\mathrm{GaN}$ 을 부분적으로 성장시켰다. ${ }^{9)}$ (Fig. 4) 이 러한 방식으로 평평한 $\mathrm{GaN}$ 광전극에 비해 광전류가 상당히 증가함을 보였다. 또한 동일 논문에서 재성장 (regrowth)에 의해 $\mathrm{GaN}$ 의 표면적을 크게 하여 광전류 가 커지는 것을 관찰하였다. 그러나 $\mathrm{GaN}$ 의 표면적이 증가한다고 반드시 광전류가 향상되는 것은 아니다. Liu 등은 성장과정에서 자연적으로 거칠어진 (naturally textured) $\mathrm{GaN}$ 경우 오히려 광전류가 줄어든다고 보고 하였다. ${ }^{10)}$ 이는 표면 결함이 증가하여 표면에서 캐리어 재결합이 증가하기 때문으로 해석되었다. 

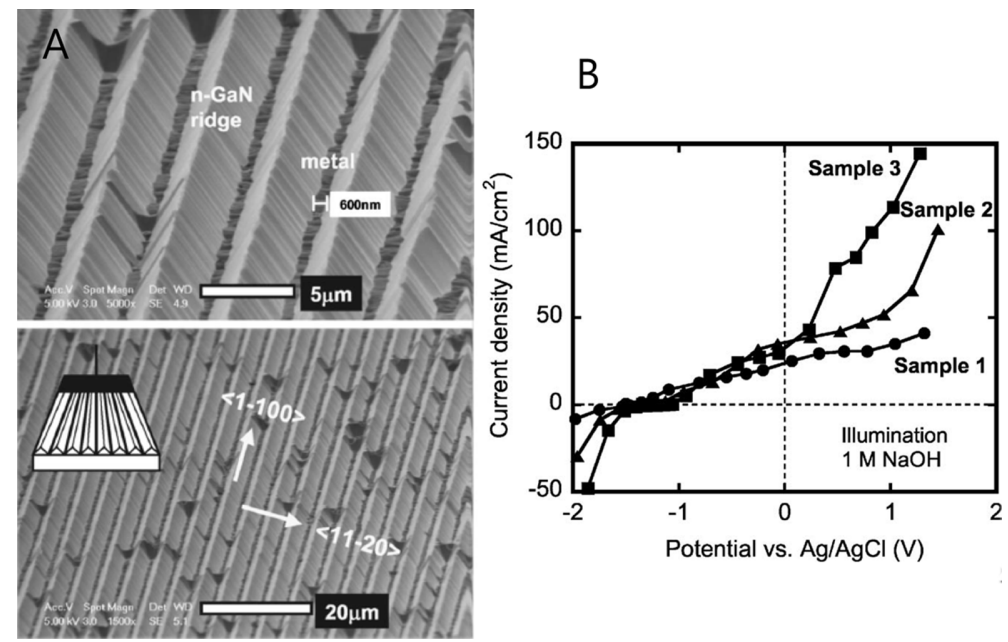

Fig. 4. (A) SEM images of sample before use, for which both metal stripes and n-GaN ridges were patterned. The stripes and ridges are aligned along $\langle 1-100\rangle$. The inset schematically illustrates the sample with an Ohmic contact electrode and a metal wire (B) Current-potential curves of plain $\mathbf{n}-\mathrm{GaN}$ sample 1, $\mathrm{n}$-GaN with metal stripes sample 2, and $\mathbf{n}-\mathrm{GaN}$ with metal stripes and $\mathrm{n}-\mathrm{GaN}$ ridges sample 3 under illumination. $1 \mathrm{M} \mathrm{NaOH}$ was used as an electrolyte. Reprinted with permission from ref. 9. Copyright 2007, AIP Publishing LLC.

한편 $\mathrm{GaN}$ 나노 구조를 이용한 물분해 실험도 보고 되었다. $\mathrm{Mi}$ 등은 ${ }^{10)} \mathrm{Si}$ 기판 위에 $\mathrm{GaN}$ 나노선을 성장 하였고 도핑을 조절하여 광전류가 변화됨을 관찰하였 다. 광자 파장 $350 \mathrm{~nm}$ 에서 undoped $\mathrm{GaN}$ 의 최대 양 자효율이 $15 \%$ 인 반면, $\mathrm{Si}$-doped $\mathrm{GaN}$ 의 최대 양자 효율은 $18 \%$ 로 증가하였다. 이것은 도핑으로 인해 결 핍층의 두께가 줄어들기 때문으로 보았다. 이러한 $\mathrm{GaN}$ 나노선 광전극의 경우 별도의 물분해 촉매를 증 착하지 않았음에도 불구하고 단락 (short-circuit) 상태 (외부전압 0)에서 상당한 광전류가 측정되었고, 이는 나노선 광전극의 전기화학적 표면적이 커서 과전압을 낮추는 효과가 있기 때문으로 보인다.

\section{3. p형 GaN 물질의 수소발생반응을 이용한 광전기화학적 수소 생산}

일반적으로 반도체 전극을 이용한 광전기화학적 물 분해에서 $\mathrm{p}$ 형 반도체 물질이 $\mathrm{n}$ 형 반도체 물질에 비해 더 많이 사용된다. 그 이유는 $\mathrm{p}$ 형 반도체는 수소환원 반응이 일어나는 광환원전극(photocathode)으로서 환 원성 분위기에서 동작하는 반면 $\mathrm{n}$ 형 반도체는 물 산 화반응이 일어나는 광산화전극(photoanode)이어서 산 화분위기에서 상대적으로 부식이 일어나기 쉽기 때문 이다. 그러나 $\mathrm{GaN}$ 물질의 경우 $\mathrm{p}$ 형 $\mathrm{GaN}$ 을 이용한 물 분해 연구는 상대적으로 적다. 그 이유는 $\mathrm{p}$ 형 $\mathrm{GaN}$ 물 질의 비저항(resistivity)이 너무 크기 때문이다. $\mathrm{n}$ 형 $\mathrm{GaN}$ 의 최대 불순물 농도가 $\sim 10^{19} \mathrm{~cm}^{-3}$ 수준임에 비해,

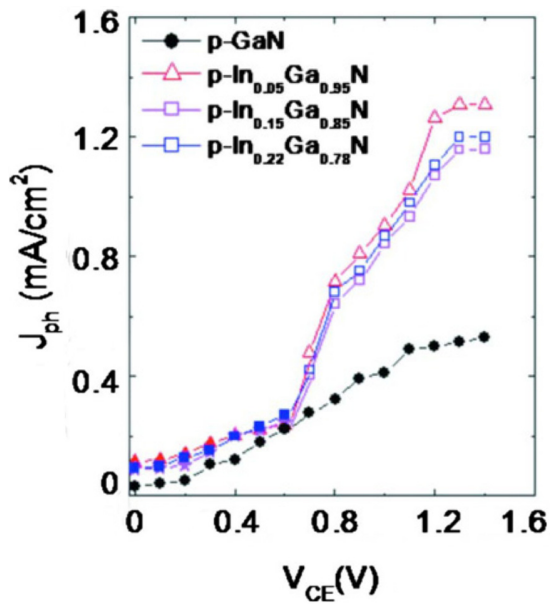

Fig. 5. Photocurrent densities $J_{p h}$ as a function of $V_{C E}$, the voltage applied between working and counter electrodes under white light illumination using a standard AM1.5 solar simulator. The light intensity at the sample surface was about $132 \mathrm{~mW} / \mathrm{cm}^{2}$. Open symbols indicate generation of $\mathrm{H}_{2}$ gas, while solid symbols indicate no $\mathrm{H}_{2}$ gas generation. Reprinted with permission from ref. 12 . Copyright 2010, AIP Publishing LLC.

$\mathrm{p}$ 형 $\mathrm{GaN}$ 은 $\sim 10^{17} \mathrm{~cm}^{-3}$ 이어서 전도도가 작다. 이는 큰 비저항으로 나타나고 일반적으로 전극 크기가 $0.1 \sim 1 \mathrm{~cm}$ 임을 고려할 때 이는 광전극 가장자리에서만 전류가 흐 르는 전류 밀집 (current crowding) 문제를 일으킨다.

전류 밀집 문제를 완화하기 위해, Sheu 등 ${ }^{11)}$ 은 격 
자 모양의 $\mathrm{ITO}$ 오믹 전극을 $\mathrm{GaN}$ 표면 상에 제작하 였다. 앞서 소개한 $\mathrm{n}$ 형 $\mathrm{GaN}$ 위 격자 오믹 전극과 유 사한 개념인데, 이러한 구조로 bare $\mathrm{p}-\mathrm{GaN}$ 전극에 비 해 광전류가 증가함을 보고하였다.

$\mathrm{p}$ 형 $\mathrm{GaN}$ 의 도핑 한계 문제를 극복하고 $\mathrm{p}$ 형 $\mathrm{GaN}$ 을 광전극으로 활용할 수 있다면, 화학적 안정성이 우수 한 $\mathrm{GaN}$ 물질이 환원전극으로 더욱 안정화되어 부식 에 강한 광전극이 될 것이다. Jiang 등 ${ }^{12)}$ 은 $\mathrm{GaN}$ 결정 격자에 $\mathrm{In}$ 을 첨가한 $\mathrm{p}$ 형 $\mathrm{InGaN}$ 물질을 이용한 물분 해 실험을 성공적으로 수행하였다. $\mathrm{p}$ 형 $\mathrm{GaN}$ 의 최대 도핑 농도가 $\sim 10^{17} \mathrm{~cm}^{-3}$ 수준이지만 $\mathrm{In}$ 을 넣어준 $\mathrm{In}_{0.22} \mathrm{Ga}_{0.78} \mathrm{~N}$ 경우 최대 도핑 농도가 $5 \times 10^{18} \mathrm{~cm}^{-3}$ 까 지 증가한다. 또한 In 첨가로 에너지 띠간격이 줄어들 어 광전류도 상당히 증가함을 보였다. (Fig. 5) 이는 현재까지 $\mathrm{GaN}$ 물질을 이용한 물분해 연구 중 가장 높은 광전류 수준이지만, 이전 논문들과 마찬가지로 물분해 촉매 없이 bare $\mathrm{GaN}$ 을 사용하기 때문에 과전 압이 상당히 크고 추가적인 외부 전압이 있어야 물분 해 반응이 진행된다.

\section{GaN 광촉매를 이용한 물분해}

본 총설은 $\mathrm{GaN}$ 기판을 광전극으로 사용하여 광전 기화학적으로 물분해를 수행하는 방식에 집중하였으 나, 이른바 '광촉매(photocatalysis)'라 불리는 물분해 방식도 언급할 만하다. 광촉매 방식에서, 일반적으로 용액에 분산된 (dispersed) $\mathrm{TiO}_{2}$ 등 반도체 입자에 빛 을 쪼여주면 개개의 입자가 산화전극과 환원전극으로 작동하여 한 광촉매 입자에서 수소와 산소가 동시에 발생된다. 광전기화학적 물분해 방식과 마찬가지로, 맨 광촉매 입자 (bare photocatalyst)는 일반적으로 수소 와 산소 발생 반응 속도가 느리므로 흔히 적당한 물 분해 촉매로 입자 표면을 담지한다. 광촉매 방식은 장 치 구성이 단순하다는 장점이 있으나 수소와 산소의 혼합기체가 생산되기 때문에 추가적으로 수소를 분리 해야 하는 단점이 있다.

Domen 그룹은 $\mathrm{GaN}$ 와 $\mathrm{ZnO}$ 의 고체 용액 (solid solution)을 제조하여 그 입자 표면을 $\mathrm{Cr}$ 과 $\mathrm{Rh}$ 으로 담지 한 광촉매를 개발하였다. ${ }^{13-17)}$ 조성식 $\left(\mathrm{Ga}_{1-\mathrm{x}} \mathrm{Zn}_{\mathrm{x}}\right)\left(\mathrm{N}_{1-\mathrm{x}} \mathrm{O}_{\mathrm{x}}\right)$ 인 이 광촉매 물질은 광자 파장 $420-440 \mathrm{~nm}$ 에서 약 $2.5 \%$ 의 양자 효율을 보이는데, 이는 기존 광촉매에 비 해 약 10 배 큰 값이다. 또한 화학적 안정성이 우수하여, 장시간 물분해 반응을 진행시킨 후에도 그 활성이 안 정적으로 유지됨을 보였다.

$\mathrm{Mi}$ 그룹은 ${ }^{18,19)}$ 기판 위에 $\mathrm{GaN}$ 나노선을 성장시켜 표면에 고정된 광촉매로 물분해를 일으키는 방식을 택 했는데, 이는 광전기화학적 방식과 광촉매 방식의 절충
이라고 볼 수 있다. $\mathrm{GaN}$ 나노선 표면에 $\mathrm{Rh} / \mathrm{Cr}$ 촉매를 증착하여 효율적으로 물분해를 수행할 수 있음을 보였 다. 또한, $\mathrm{In}$ 을 첨가한 $\mathrm{InGaN} / \mathrm{GaN}$ core/shell 구조를 제작해 양자효율이 $27 \%$ 에 이르는 고효율을 달성했다.

\section{5. 향후 과제}

$\mathrm{GaN}$ 물질을 이용한 다양한 물분해 연구에도 불구하 여 여전히 몇 가지 과제가 남아 있다. 우선, 적절한 전 기촉매로 $\mathrm{GaN}$ 표면에 증착시키는 연구가 필요하다. 기 존 대부분의 연구에서 별도의 물분해 전기촉매가 증착 되지 않은 bare $\mathrm{GaN}$ 을 이용했기 때문에 과전압이 크 고 띠 이론적으로 충분히 자발적 물분해가 가능한 상 황임에도 실제로 그것을 구현하지 못하고 있다. 전기촉 매 증착 방법에 대한 연구뿐 아니라, 다른 전기촉매/반 도체에 적용되는 이론 (pinch-off theory 등)이 $\mathrm{GaN}$ 경우에도 적용되는지에 대한 연구가 필요하다. ${ }^{20,21)}$

두 번째로, 새로운 기판에 성장된 $\mathrm{GaN}$ 을 이용한 연 구가 필요하다. 기존 $\mathrm{GaN}$ 성장은 주로 사파이어 기판 위에 진행되었는데, 이 기판은 상당히 고가이어서 실 용성이 떨어지고 부도체이므로 셀 구성에 어려움이 발 생한다. 저렴한 $\mathrm{Si}$ 이나 스텐레스 기판 등에 $\mathrm{GaN}$ 을 성 장시켜 광전극으로 활용할 수 있으면 실용성이 높은 물분해 소자를 제작할 수 있을 것이다. 또한, $\mathrm{p}$ 형 $\mathrm{GaN}$ 의 활용성도 높아질 것인데, 앞서 서술한 바와 같 이, $\mathrm{p}$ 형 $\mathrm{GaN}$ 은 비저항이 높아 전류 밀집 문제가 생 기는데 도체 혹은 반도체 기판 위에 $\mathrm{p}$ 형 $\mathrm{GaN}$ 이 있으 면 이러한 문제가 훨씬 완화될 것이다. 그리고 $\mathrm{p}$ 형 $\mathrm{GaN}$ 은 환원 분위기에서 동작하므로 $\mathrm{n}$ 형 $\mathrm{GaN}$ 에 비해 수명이 상당히 증가할 것이다.

\section{감사의 글}

이 연구는 금오공과대학교학술연구비에 의하여 지 원된 논문임

\section{참고문헌}

1. J. A. Turner, 'Sustainable Hydrogen Production' Science, 305, 972 (2004).

2. M. G. Walter, E. L. Warren, J. R. McKone, S. W. Boettcher, Q. Mi, E. A. Santori, N. S. Lewis, 'Solar Water Splitting Cells' Chem. Rev, 110, 6446 (2010).

3. A. Fujishima, K. Honda, 'Electrochemical photolysis of water at a semiconductor electrode' Nature, 238, 37 (1972).

4. K. Fujii, T. Karasawa, K. Ohkawa, 'Hydrogen gas generation by splitting aqueous water using n-type $\mathrm{GaN}$ photoelectrode with anodic oxidation' Jap. J. Appl. Phys., 
44, L543 (2005).

5. K. Fujii, K. Ohkawa, 'Hydrogen generation from aqueous water using n-GaN by photoassisted electrolysis' physica status solidi (c), 3, 2270 (2006).

6. K. Fujii, M. Ono, T. Ito, Y. Iwaki, A. Hirako, K. Ohkawa, 'Band-edge energies and photoelectrochemical properties of n-type $\mathrm{Al}(\mathrm{x}) \mathrm{Ga}(1-\mathrm{x}) \mathrm{N}$ and $\mathrm{In}(\mathrm{y}) \mathrm{Ga}(1-\mathrm{y}) \mathrm{N}$ alloys' J. Electrochem. Soc., 154, B175 (2007).

7. J. Li, J. Y. Lin, H. X. Jiang, 'Direct hydrogen gas generation by using InGaN epilayers as working electrodes' Appl. Phys. Lett., 93, 162107 (2008).

8. S.-Y. Liu, J. K. Sheu, C.-K. Tseng, J.-C. Ye, K. H. Chang, M. L. Lee, W. C. Lai, 'Improved Hydrogen Gas Generation Rate of n-GaN Photoelectrode with $\mathrm{SiO} 2$ Protection Layer on the Ohmic Contacts from the Electrolyte' J. Electrochem. Soc., 157, B266 (2010).

9. I. Waki, D. Cohen, R. Lal, U. Mishra, S. P. DenBaars, S. Nakamura, 'Direct water photoelectrolysis with patterned n-GaN' Appl. Phys. Lett., 91, 193519 (2007).

10. B. AlOtaibi, M. Harati, S. Fan, S. Zhao, H. P. T. Nguyen, M. G. Kibria, Z. Mi, 'High efficiency photoelectrochemical water splitting and hydrogen generation using $\mathrm{GaN}$ nanowire photoelectrode' Nanotechnology, 24, 175401 (2013).

11. S.-Y. Liu, J. Sheu, M. Lee, Y.-C. Lin, S. Tu, F. Huang, W. Lai, 'Immersed finger-type indium tin oxide ohmic contacts on $\mathrm{p}-\mathrm{GaN}$ photoelectrodes for photoelectrochemical hydrogen generation' Optics Express, 20, A190 (2012).

12. K. Aryal, B. N. Pantha, J. Li, J. Y. Lin, H. X. Jiang, 'Hydrogen generation by solar water splitting using $\mathrm{p}$ InGaN photoelectrochemical cells' Appl. Phys. Lett., 96, 052110 (2010).

13. N. Arai, N. Saito, H. Nishiyama, K. Domen, H. Kobayashi, K. Sato, Y. Inoue, 'Effects of divalent metal ion $\left(\mathrm{Mg}^{2+}, \mathrm{Zn}^{2+}\right.$ and $\left.\mathrm{Be}^{2+}\right)$ doping on photocatalytic activity of ruthenium oxide-loaded gallium nitride for water splitting' Catalysis Today, 129, 407 (2007).

14. N. Arai, N. Saito, H. Nishiyama, Y. Inoue, K. Domen, K. Sato, 'Overall water splitting by $\mathrm{RuO} 2$-dispersed divalent-ion-doped $\mathrm{GaN}$ photocatalysts with $\mathrm{d}(10)$ electronic configuration' Chem. Lett., 35, 796 (2006).

15. K. Maeda, K. Domen, 'Solid Solution of GaN and $\mathrm{ZnO}$ as a Stable Photocatalyst for Overall Water Splitting under Visible Light' Chem. Mat., 22, 612 (2010).

16. K. Maeda, T. Takata, M. Hara, N. Saito, Y. Inoue, H. Kobayashi, K. Domen, 'GaN : ZnO solid solution as a photocatalyst for visible-light-driven overall water splitting' J. Am. Chem. Soc., 127, 8286 (2005).

17. K. Maeda, K. Teramura, D. Lu, T. Takata, N. Saito, Y. Inoue, K. Domen, 'Photocatalyst releasing hydrogen from water' Nature, 440, 295 (2006).

18. B. AlOtaibi, H. P. T. Nguyen, S. Zhao, M. G. Kibria, S. Fan, Z. Mi, 'Highly Stable Photoelectrochemical Water Splitting and Hydrogen Generation Using a DoubleBand InGaN/GaN Core/Shell Nanowire Photoanode' Nano Letters, 13, 4356 (2013).

19. D. F. Wang, A. Pierre, M. G. Kibria, K. Cui, X. G. Han, K. H. Bevan, H. Guo, S. Paradis, A. R. Hakima, Z. T. Mi, 'Wafer-Level Photocatalytic Water Splitting on GaN Nanowire Arrays Grown by Molecular Beam Epitaxy' Nano Letters, 11, 2353 (2006).

20. I. Oh, 'Silicon Nanostructures Fabricated by MetalAssisted Chemical Etching of Silicon' J. Korean Electrochem. Soc., 16, 1 (2013).

21. Hyun Sik Kim, Sang Kwon Lee, Soon Hyung Kang, 'Preparation and Photoelectrochemical Behavior of $\mathrm{Cu}_{2} \mathrm{O}$ / $\mathrm{TiO}_{2}$ Inverse Opal Heterojunction Arrays' J. Korean Electrochem. Soc., 15, 149 (2012). 